\title{
The Transformation of Traditional Dance from Its First to Its Second Existence: The Effectiveness of Music - Movement Education and Creative Dance in the Preservation of Our Cultural Heritage
}

\author{
Lykesas Georgios \\ Correspondence: Lykesas Georgios, School of Physical Education and Sport Science, Aristotle University of \\ Thessaloniki, Greece.
}

Received: November 26, 2017

Accepted: December 19, 2017 Online Published: December 22, 2017

doi:10.11114/jets.v6i1.2879

URL: https://doi.org/10.11114/jets.v6i1.2879

\begin{abstract}
Being an indispensable part of our folk tradition, the traditional dance bears elements of our cultural tradition and heritage and passes them down from generation to generation. Therefore, it contributes substantially to the reinforcement of our cultural identity and plays a crucial role in the "cultural development" of our society.

Our culture is going through a constant process of mutation. Some traditional elements get lost, while others resist and survive or get transformed and readjust to new emerging circumstances.

The aim of the present study is to investigate the learning process of Music/ Movement Education and Creative Dance within the context of the "second existence" of dance, and the way in which this learning process can effectively save and preserve the characteristic cultural traits of the "first existence" of the traditional dance.

The experiential way of learning and transmitting dance from one generation to the other, is characterized as "the first existence" of dance. Changes in modern social, political and economic conditions have influenced the Greek traditional dance, which has acquired a more entertaining and tourist-commercial character, while its educational character has transformed going through teacher-centered educational processes. Having undergone this change, the traditional dance is now defined as "the second existence" of folk dance. The conversion of the traditional dance from its "first existence" into its "second existence" is supported and interpreted by the three components of the dancing process, the so-called "communication triangle": the dancer, the dance and the viewer. The adoption of the particular approach of Music Movement Education and Creative Dance in teaching Greek traditional dances can preserve and convey a large part of our cultural heritage to the new generation.
\end{abstract}

Only by learning their country's history and culture will the young generations be able to learn their own identity and make the best of the past in order to live more happily today and create a better future.

Keywords: traditional dance, first and second existence, music and movement education, creative dance, communication triangle

\section{Introduction}

The political, economic and cultural changes of the last decade have led to new trends and challenges in the field of dance education (Tsaousis, 1993). Rapid advancements in the economic, social and technological sector have contributed to the gradual decline of folklore cultural elements and, as a consequence, have resulted in the shrinkage and degradation of music \& dance tradition in traditional rural communities (Meraklis, 1989). More particularly, the disorganization of the province and the urban transformation of the Greek society have affected traditional practices and structures of the social fabric. Therefore, cultural elements of the past have not remained intact, but are constantly being renewed and modified. Throughout this constant mutation, many traditional features get lost, while others resist and survive or get transformed and readjust to new emerging circumstances (Meraklis, 1973). The renewal and regeneration of old cultural features is inevitable - particularly, when it comes to oral tradition that passes down through generations by word of mouth. As there are changes occurring in social and political institutions, human values, ideals and lifestyle (Dimas, 2010), the Greek traditional dance could not possibly be cut off from the social, economic and ideological circumstances that have led to its structural and functional transformation (Koutsouba, 2007, 2010). 
The "Dromena" (dramatic happenings) are rituals or theatrical acts enriched with speech, songs and dances. The "actors" are ordinary people as protagonists of a folk theater. According to Puchner, the pure features of the folk theater are "collective production and acceptance, active participation of the audience in the performance, common aesthetics, standardization and improvisation, leading to a commonly accepted tradition (Puchner W, 1983, 1989).

"Dance" is probably the best way to learn the rhythm and also learn how to control our instinctive drive for movement. It is through free movement, that one acquires their autonomy by learning to freely express themselves, expand their perspective and realize the terms of proper teamwork (Kapsalis, 1977; Haselbach, 1979; Sanderson, 1988). Dance is also a spatiotemporal art, a continuous sequence of activities that evolve in space and time (Tyrovola, 2001). It is also characterized as a non-competitive motor activity that promotes health, improves physical fitness and develops flexibility, strength, stamina, balance, rhythmic ability, neuromuscular coordination, synchronization and body control (Churcher, 1971; Sanderson, 1988; Brinson, 1991). "Creative dance" is a special form of dance which combines the knowledge of movement with the art of expression (Laban, 1981; Lykesas, 2002b, 2008, 2009; Gilbert, 2015). Through Creative Dance, one can express their inner thoughts, emotions and ideas, consciously using simple daily body movements, without requiring the knowledge of any particular and sophisticated dance technique (Bergmann, 1995; Gilbert, \& Rossano, 2006; Lykesas et Al., 2014; Gilbert, 2015; Amado, et al., 2017). Creative dance aims at the global personality development of individuals, preparing them for their successful participation in public, economic and cultural life (Dimondstein, 1974; Stinson, 1988; Davis, 1995; Tyrovola, 2010; Koutsouba, 2000, 2007). When dancing, one actually 'talks' with their self and with the community at the same time. In this way the community reinforces its cohesion, gets connected with their past where values derive from, gets amused and delivers folk tradition by repetition, continuity and word of mouth (Tyrovola, 1999). The dance movement is the most natural and direct way of reacting to music, and therefore contributes to the deeper feeling and understanding of music (Lai Keun \& Hunt, 2006). The combined action of music and movement has been named "Music - Movement Education", which is the combination of music, movement and speech(Orff, 1963; Antonakakis, 1996). Music, speech and movement compose an integrated whole without the one being subordinated to the other (Orff, 1963; Matey, 1992). Music - Movement Education is based on creativity, active participation and living experience. It uses experimentation, exploration, observation, free expression and creative improvisation (Siemens, 1969; Morgan, et al., 1970; Bubner, et al., 1982; Moore, 1984; Androutsos, 1995; Lykesas, 2002). The characteristic features of Music - Movement Education are very much in line with the nature of the "Greek traditional dance" which, besides "uniformity, cohesion and duration in time", also includes creativity, collectivity, improvisation and constant transformation, which are all, concepts opposed to standardization and consolidation (Damianakos, 1984; Lykesas et al., 2008; Koutsouba, 2007, 2010). The Greek traditional dance also conveys and passes down through generations elements of cultural tradition and heritage, items of historical, folklore and geographical knowledge; it contributes to determining cultural identity and plays a highly significant role in the society's "cultural development" (Collinson, 1973, Best, 1982; Koutsouba, 2003; Lykesas et al., 2006, 2010b). This way of learning dance and transmitting traditional cultural knowledge and experiences through dance, is characterized as "the First Existence" of dance (Hoerburger, 1965, 1968, Damianakos, 1984, Bratopoulou 1994, Filippidou, et al, 2008; Koutsouba, 2010; Filippou, 2015). Furthermore, the traditional dance represents society itself as it provides artistic/dancing expression, entertains, teaches and nurtures through the dynamics of rhythmic movements. By participating in dance movement activities, individuals discover their rhythm, reveal their expressive improvisational and creative skills, cultivate and improve their interpersonal relationships, communication and collaboration not only with other participants in these dance activities but also with the broader social environment. (Lykesas et al., 1999, 2002, 2008, 2009, 2010, 2014). Once recognizing the functions that accompany dance, one easily understands the dance process itself. As these functions are closely interwoven and directly presented through the dance act, identifying them helps us understand and interpret the dance phenomenon. Therefore, systematic observation and analysis of dance movements, complexity and style, reveals the significance that dance has for its creator, the dancer and the viewer, while at the same time it reflects the norms, opportunities and ideas of the social construction with which it is directly connected (Tyrovola, 2003; Panopoulou \& Goulimaris, 2010). The dance phenomenon is by no means easy to define. In order to fully understand it, the researcher should first know the community dance to a satisfactory degree, so as to adequately approach other cultural fields -such as kinship, social organization, rituals- that are directly connected with the dance. Besides, there is no doubt that when dancing one comes face to face with their own self and gets more familiar with their body and body use in terms of space, time and dynamics. Dance enhances their ability to read and decode the quality of their motion and moving body, to interpret ideas and emotions symbolically through their body movements (Gilbert, 2015). Due to dance complexity, dancers are required to demonstrate concentration and movement synchronization, and also listen carefully to the music and melodic changes that constitute the cue for every corresponding movement. Being aware of the close relationship between music and dance (movement), viewers traditionally participate with applause and exclamations, praising the dancers' virtuosity, grace and harmony (Lykesas, 2007, 2016). The interpretation of the dance phenomenon is based on the fact that dance 
is a means of communication and can be explained according to the "Communication Triangle": transmitter - message - recipient. Being a dynamic process of the local community, dance has acquired some "modern elements" since transferred to the stage and teaching classrooms, having acquired a more entertaining and commercial character. When moving to stage, the traditional dance is cut off from its natural environment, consolidates in space and time and is converted into a mechanistic process placing emphasis on the form image and final result, having lost its polysemous social, symbolic and cognitive content (Koutsouba, 2010). This has greatly influenced the Greek traditional danc, which under these new circumstances has acquired a more entertaining and commercial character. At the same time, its educational character has been significantly modified through specific educational processes. In this sense, the traditional dance is defined by the term "Second Existence" (Hoerburger, 1965, 1968; Koutsouba, 1991, 2011; Nahachewsky, 2001; Filippidou et al, 2008; Lykesas, 1999, 2004, 2016).

The aim of the present study is to investigate the effectiveness of the learning process of Music - Movement Education and Creative Dance within the context of the "Second Existence" of the traditional dance, so as to save and preserve the main characteristic cultural elements of its "First Existence".

\section{The Process of Communication and Interpretation of the Dance Phenomenon}

The interpretation of the dance phenomenon is based on the fact that the dance is a communication means serving various purposes and functions that could be ranked according to the "communication triangle" (transmitter-message-receiver) and determine the transformation parameters (Bratopoulou, 1994 ).

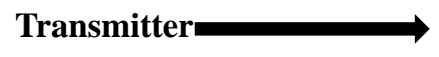

(Dancer)

\section{Message}

(Dance Act)

\section{Recipient}

(Viewer)

The transmitter refers to the "dancer", the message to the "dance act" and the receiver to the "viewer" (Pita, 1998). The communication process begins when the dancer wishes to pass on information to the viewer/s. Then the dancer (transmitter) encodes what s/he wants to convey using a code of movements and forms a message. Through the dance act, s/he conveys the message to the viewer (recipient). The viewer then receives the message, decodes it, interprets it, and ultimately recognizes, perceives, understands, feels what the dancer wished to carry forward. This form of communication usually has the desired effect; it affects the viewer's or viewers' knowledge, thoughts, feelings and behavior, and has to do with the projection of the "aesthetic aspect" of dance. In this case we have the form of "experiential function" where the dancer and the viewer have direct communication with each other and identify themselves with the message. The dancers are interested in how to transmit their messages through the dance act, thus placing emphasis on the form of dance. This emphasis promotes the aesthetic aspect of dance, as mentioned above, which is stated through the dance movement thanks to the dancers' harmony, grace, pleasure and dancing ability. In this case, the viewers participate actively once receiving the message, and this participation is expressed with applause, exclamations and gestures.

\section{Dancer \\ Dance Act \\ Viewer}

\section{(Aesthetic aspect}

(As communication means)

(Direct)

\section{(Experiential function)}

This dancer-viewer communication presupposes a common aesthetic language, which is one of the main traits of oral tradition determining the emotional reaction and direct contact between the viewer and the dancer (Lykesas, 2016). Thus, the aesthetic function of dance is directly related to the fulfilled social function from which the dance derives its true meaning. This is done on the basis of the close relationship between form and content of the dance act, and depends on common codes and needs allowing a consistent interpretation by society itself (Damianakos, 1984). This function form of dance is also characterized by "collectivity, oral tradition and anonymity" in passing down knowledge and experiences from generation to generation (i.e. through experiential learning) and is known as the "first dance existence" (Hoerburger, 1965, 1968, Damianakos, 1984, Bratopoulou 1994, Filippidou et al, 2008, Koutsouba, 2010b). In the opposite case, i.e. when the two-way communication takes place and the target of communication is the viewer (recipient), it is the "artistic aspect" that is promoted during the dance performance. The communication between the dancer and the viewer is indirect and gets perceived through the dance act. This artistic dance act is a product of practice and preparation in the premises of cultural associations, schools and universities, and as a result there are no intense improvisation and creative elements. So, the messages sent to the viewer aim at making good impressions and are not so much emotionally charged as used to be in the "primary form" of dance that had to do mostly with the "experiential" learning process from generation to generation. This is due to the fact that the dance act has moved away from its natural environment to a stage which in its turn imposes limitations with regard to placement, shifting and formation of movements; as a result, it is the so-called "conative function" that prevails. Besides, having different experiences in an environment that is different from where the dance originates, viewers cannot be emotionally touched by the way the 
dance is performed.

\section{Dancer $\longrightarrow$ Dance act \\ (As communication means) \\ Viewer \\ (Artistic aspect) \\ (Conative function) \\ (Indirect)}

Something similar happens with younger dancers, who may have contact only occasionally -if any- with the country or region of origin of the dances they are taught, and are asked to convey experiences that are unknown or unfamiliar to them. So, the younger dancers who have not lived in the environment of every community, have neither listened to nor seen the dance performed on the traditional dance floor on the village square. So, they do not have the chance to observe, to sense, to assimilate and understand all those important elements, such as functionality, local dancing idiom and style of dance movement. The difficulty to understand all the above is due to the different experiences of older and younger generations. In addition, the relationship and directness of communication that used to exist between musicians and dancers at local feasts, is no longer present during dance lessons or preparation of performances in Dance Associations. As a result, younger dancers have difficulties in learning and generally understanding traditional dances. Following World War II and the Industrial Revolution (1950), a new cultural and social environment was created due to the internal migration - urbanization and adjustment of the rural population to the new living conditions. This migration played an important role in shaping and changing the traditional music-dance idiom (Loutzaki, 1985; Drandakis, 1993; Sbonias, 1999). Also, developments and changes in the economic life and social organization, along with the spread of tourism, have contributed significantly to the dynamic transformation from the "older" to the "newer". Thus, the social function of dance ceased to exist as the closed society opened up and was no longer isolated. The abandonment of the local community, the settlement of the biggest part of population in larger cities and their need to keep in touch with their tradition led to the creation of Cultural Associations with the aim of spreading and disseminating their local music and dancing tradition (Meraklis, 1989). The changing environment, the difficulty of the younger ones to learn local dances, the different audiences they were addressed to, had direct consequences: dances acquired simpler forms with changes in dance groups, combinations and alternations of choreographic parts and dancing patterns. In this way, the traditional folk dance has gained another status which is described with the term "Second Existence" implying the above transformation (Loutzaki, 1989; Koutsouba, 1991; Lydaki, 2008; Koutsouba, 2007, 2009).

It is widely accepted that dances in the traditional community used to have an experiential character and were approached as an indispensable part of the social fabric, directly connected to the social, material and spiritual life of the people who lived in it. The simple dancers of the community would transmute their deepest sensations and feelings through the emphatic use of lower limbs and subordination to rules related to hand movements and body twists (Tyrovola \& Koutsouba, 2006; Lidaki, 2008). Moving in space and time, they would get inspired, discover, improvise, compose and 'color' their movements, accompanied by the music or song of the dance, turning their body from an object of management and mechanistic repetition into an active element of social action (Koutsouba, 2010; Lidaki, 2008).

\section{The Phenomena of "First" and "Second" Existence of Dance}

The phenomena of "first" and "second existence" of dance are determined by particular features. More specifically, In its "first existence" (elsewise called "first form" or "primary form"), dance is an "indispensable part of all members of a social group" (Koutsouba, 2010). In the past, dance used to serve as a vital link and communication means among the people of a local community. By dancing, the people of the community would actually 'talk' to each other and to those watching them, would reveal their inner self with passion and precision reflecting their ideology, worldview, beliefs and common feeling. Participation in the dance act was characterized by teamwork and common spirit, while dance integrated with music and singing- representing the cultural identity and expression of every local community (Antzaka-Bei, \& Loutzaki, 1999). The traditional dance is also characterized by "improvisation" of both the dancers and the first dancer (Drandakis, 1993; Tyrovola, 1999; Koutsouba, 2010). The transmission and function of dance is characterized as "experiential", since individuals learn to dance from an early age by participating in the various music and dance feasts of their community, observing and assimilating all characteristic elements and local idioms for every single dance. The children would participate in the beginning as spectators watching all happenings. Then they would hold at the end of the circle and try to copy the adults. It was in this way that they learnt how to dance -something that is happening today in very few areas of Greece (Lykesas, 1999, 2016). Thus, the knowledge that passes on from generation to generation, enhances the sense of common cultural identity and continuity, and connects the present with the past and the future (Koutsouba, 2010, Lykesas, 2016). The traditional dance aims at reducing any sort of formalism and expressing feelings in new ways every time. Every dancer must improvise using an original technique, their spontaneity and explicitness. It is through movement that dancers experiences "by instinct" and express openly the emotions and history of their birthplace. In this way they are able to unfold spontaneously a wide range of ideas and emotions. Feelings are experienced "unconsciously" 
over and over again through movements and unfold freely with extremely expressive power, in order to flare up again with every new experience (Haselbach, 1979; Koutsouba, 2010). The phenomenon of "second existence" of dance is characterized by elements that come in contrast to the "first existence" of dance. Dance has left its natural place of performance, i.e. the traditional dance floor ('horostasi') on the village square, and operates in a different environment far from its place of origin. It is thus limited to stage performance and is no longer a functional part of all members of a community; instead, it has become an occupation of a "specific group" or "individuals" through dance cultural associations and schools. As a result, the local music and dance repertoire has gotten lost or transformed over time (Dimas, 2010). The phenomenon of "second existence" of dance as a product of practice and preparation in dance classrooms and schools, does not present a high degree of "improvisation", "creativity" and complexity, resulting in simpler poorer forms, with identical dance movements performed by the entire dancing group (Koutsouba, 2010; Filippou, 2015). The traditional local music and dance tradition used to be learnt "experientially" and passed down through generations -with symbiotic social groups shaping and adopting the repertoire, group arrangement, form and style of dances (Nitsiakos, 2003; Dimas, 2010). Today in the "second existence" of traditional dance, music and dance tradition is taught by specialized dance instructors and folk musicians who act as mediators of music-dance knowledge. Following this type of teaching, they cover almost all regions of Greece without having though knowledge of local particularities and features of the various local social groups (Tyrovola, 2010, Koutsouba, 2010). This sort of teaching and transmission is conducted in a purely teacher-centered way characterized by "passive repetition" and "passive behavior". In other words, it is a "mimetic reproduction of dance movement" where dance movements appear to be fixed, standardized and structured, depriving the traditional dance from its rich and varied range of forms (Damianakos, 1984; Dimas, 1989; Tyrovola, 2010; Lykesas, 2006, 2007). Today, traditional dance movements are carried out "in a conscious way" following a strictly stereotypical process that has nothing to do with the creative oral traditional process of folk dances. The teacher-centered form of the "second existence" of traditional dance, is not compatible either with the traits and nature of the popular oral tradition or with the "constant transformation" of traditional dances.

\section{The Nature of Greek Traditional Dance and Creative Teaching Models}

In order to understand the nature of traditional folk dances, we should refer to the concept of folk tradition (Damianakos, 1984; Tyrovola, 1999; Koutsouba, 2007).

"Tradition" is the knowledge that has been stored within a long period of time in a society of people and passes down from generation to generation. This knowledge has to do with songs, dances, fairy tales, dramatic performances etc. that change over time. As social and political institutions, human values, ideals and lifestyle undergo changes, the same happens with tradition.

(Kiriakidou - Nestoros, 1993). The notion of folk tradition has to do with the anonymous creative process and transmission by word of mouth that result in continuous differentiation and constant transformation (Drandakis, 1993). The primary features of folk tradition are its spontaneous expression and experiential function. As part of folk tradition, the traditional dance is characterized by word of mouth, creativity, collectivity, anonymity, improvisation, vitality, energy, change and constant transformation (Koutsouba, 2007). The cultural elements of the past are constantly renewed and shaped within the traditional society itself. Throughout this mutation, some elements get lost, others remain intact or readjust to the new emerging circumstances (Meraklis, 1973). As already mentioned, this phenomenon has been named the "first existence" of dance by Greek and foreign scholars (Hoerburger, 1965, 1968, Nachachewsky, 1995, 2001; Koutsouba, 1991, Filippidou et al., 2008). In recent decades, folklorisation, museisation and teaching practices of the Greek traditional folk dance have led to a standardized and consolidated teaching method negating and removing every aspect of creative development. Taking into account the traits of the "second existence" of dance, as well as the relations developed according to the "communication triangle" concerning "conative function", there are questions arising. Is it possible to have such an educational process within the context of the "second existence" of dance that can save and preserve cultural elements of the "first existence"?

Going through literature on creative teaching models and particularly "Music and Movement Education" and "Creative dance", it becomes evident that it is the "learner-centered" teaching method that prevails combined with "guided discovery" and "divergent productivity" (Lykesas, 2002; Lykesas \& Koutsouba, 2008; Lykesas et al, 2009). These teaching models are ruled by creativity, improvisation, expressiveness, experiential and energetic learning, development of motor, cognitive, perceptual, emotional and social skills -elements that are all consistent with the concept of the "first existence" of dance.
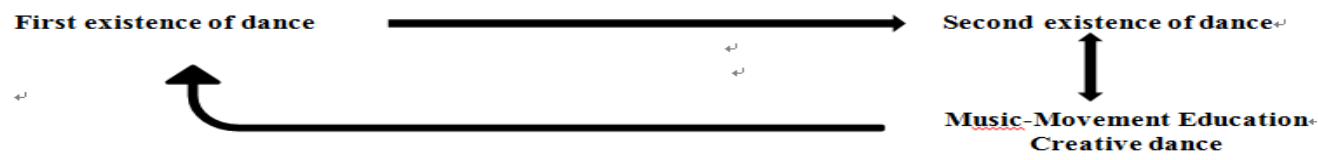
Music - Movement Education and Creative Dance can constitute the educational and methodological teaching methods so that the traditional cultural elements of the "first existence"(song, dance, dramatic performances etc) are saved and preserved or restored to the best extent to their previous state. The children get informed about the content of a dramatic performance through photographs and audiovisual material, texts, songs and dances that are integrated in the performance, as well as through narratives by people. Then follows the distribution of roles and scripts among them. They participate in role-plays, in games to understand and feel the rhythm of the music and various movement patterns with the use of songs. They also experiment with rhythmic-kinetic games and movement improvisations, get familiar with techniques for communicating and expressing themselves by using their body language, gestures and facial expressions. This form of experiential learning is achieved with the implementation of Music - Movement Education and Creative Dance that stimulates the participants' pleasure and interest while improving their interpersonal relationships. By improvising, understanding and feeling the rhythm and movement, children are easily led to experiential learning of traditional dances and songs, and getting acquainted with the cultural heritage of their homeland.

\section{Conclusions- Suggestions}

The adoption of creative teaching methods and styles, such as those of Music - Movement Education and Creative Dance, can enhance and save a large part of our cultural heritage. Similar results are pointed out by Lykesas (2002) and Koutsouba (2003). Such an educational supports and preserves all characteristic elements of the "first existence" of dance and special relationships developed according to the "Communication triangle ", which have unfortunately gotten lost within the context of the "second existence "of dance. The above findings are consistent with studies by Filippidou et al. (2008), Dima (2010) and Koutsouba (2010). Lykesas et al. (2006, 2007 \& 2010) have demonstrated that the creative teaching methods of Music - Movement Education and Creative Dance have a positive effect on learning Greek traditional dances. This is also in line with findings by Morgan et al. (1970) and Bubner et al. (1982), who report that spontaneous activities promote children's motor creativity. Therefore, when integrated into the school curriculum, they provide motivation and ensure a pleasant and interesting lesson. Similar results were also found in studies by Lykesas \& Zachopoulou, (2006) Tyrovola \& Koutsouba (2006) and Lykesas, Tsapakidou \& Tsopmanaki (2014). Amado et al (2017) have shown that the implementation of a creative dance program for girls and boys in secondary schools improved the creativity, cognitive level, emotional skills and social behavior of children -mostly of girls compared to boys. Thus, music-movement activities contribute to conveying and disseminating experiential elements of folk tradition and historical heritage, while at the same time they enhance the cultural identity and substantially affect the "cultural development" of the society. Similar findings are consistent with studies by Koutsouba (2010 \& 2010b). The effectiveness of Creative Dance is also supported by research findings of Lai Keun and Hunt (2006) and Gilbert (2015), who support that creative dance taught at $1^{\text {st }}$ elementary school graders has activated not only their physical-kinesthetic perception but also their verbal, spatial, music, interpersonal and intrapersonal perception. Similar results are supported by Dimondstein (1974) and Davis (1995), who have demonstrated that Creative Dance provides a variety of motor skills, promotes co-operation, leadership and critical thinking, and creates the appropriate environment supporting the uniqueness of every child.

The teaching and learning of Greek traditional dances will be more effective and successful when the wider aim is not only to preserve and continue our cultural heritage but also to make students love Greek traditional dances and acquire a cultural identity. By implementing a more effective teaching method of Greek traditional dances, Music - Movement Education and Creative Dance can fill in this gap and contribute substantially to the promotion and upgrading of School Physical Education, while covering at the same time the absence of dancing experience and practice at schools. In addition, Music - Movement Education and Creative Dance are consistent with the nature of Greek traditional dances that integrate the concepts of creativity, collectivity, improvisation, energy, vitality, change and constant transformation, while responding to the requirements of the new curricula of Primary and Secondary Education. Similar findings can be found in studies by Koutsouba, (2007), Lykesas and Tyrovola (2007b). The philosophy and goals of the proposed creative teaching methods need to be adopted and implemented by Physical Education teachers to save and preserve Greek traditional dance but also because they offer children opportunities to develop their self-expression, self-motivation, self-esteem and social skills. The objectives of traditional dance in today's school education need to be revised so that they are identified as a distinct field of School Physical Education. It is highly imperative to design intervention programs enriched with music-kinetic activities for these will teach Greek traditional dances with care and sensitivity. They will also help trainees learn basic elements of their cultural heritage and acquire cultural literacy. The proposed music-movement and creative dance educational model introduces a new dimension in the teaching process of Greek traditional dances, while at the same time fills in the gap of dance experience and practice in schools.

Only by raising the children's awareness about tradition, will they become conscious of their country's history. By getting in contact with their cultural heritage, they are able to recognize how the past is connected with the present. 
Being aware of their cultural identity helps them substantially create their present and plan their future with confidence. Only by learning their history and culture, can children turn elements of yesterday into powerful weapons for today and tomorrow.

\section{References}

Amado, D., Sa'nchez-Miguel, P. A., \& Molero, P. (2017). Creativity associated with the application of a motivational intervention program for the teaching of dance at school and its effect on both genders. PLOS ONE, 12(3), 1-14.

Androutsos, P. (1995). Music teaching methods. (Ed.) Orpheus. Athens. Greece.

Antonakakis, D. (1996). Carl Orff. Orfefs, Iraklio-Kreta. Greece

Antzaka-Bei, E., \& Loutzaki, R. (1999). Dance in Greece. Educational Encyclopaedia, 28, 327-341. Special Tribute: "Music. Dance. Cinema. Theatre". Ekdotiki Athinon Editions, Athens.

Bergmann, S. (1995). Creative dance in the education curriculum: Justifying the unambiguous. Canadian Journal of Education/Revue Canadienne de l'Education, 156-165.

Best, D. (1982). The aesthetic and artistic. Philosophy, 54, 357-72.

Bratopoulou, B. (1994). The factors that affected the transformation of the folk dance Sousta of Amorgos. Journal Ethnologia, 3, 85-117.

Brinson, P. (1991). Dance as education. London: Falmer Press.

Bubner, C., \& Mienert, C. (1982). Bausteine des Darstellenden Spiels. Hirschgraben Verlag. Frankfurt am Main.

Churcher, B. (1971). Physical education for teaching. London: Allen \& Unwin.

Collinson, D. (1973). Aesthetic education. In: G. Langford \& D.J.O. Connor (ed.). New essays in the philosophy of education. London: Routledge \& Kegan Pant, 210-212.

Damianakos, S. (1984). Folk Culture: Ideological use and theoretical constitution of the term. Journal Scientific thought. $19,52-61$.

Davis, J. (1995). Laban Movement Analysis: A key to individualizing children's dance, Journal of Physical Education, Recreation \& Dance, 66(2), 31-33.

Dimas, I. (1989). The traditional dance in Syrrako. Folklore and Anthropological Approach Ph.D. Thesis, Ioannina, University of Ioannina, Department of History \& Archaeology, School of Philosophy, Ioannina, Greece.

Dimas, I. (2010). Society and Greek Traditional Dance, and teaching of Greek traditional dances. In I. Dimas V. Tyrovola, \& M. Koutsouba, Greek Traditional Dance: consideration of speech, writing and its teaching, (Editors are the writers), Athens, 17-64.

Dimondstein, G. (1974). Exploring the arts with children. New York: MacMillan Publishing.

Drandakis, L. (1993). Improvisation in Greek folk dance. Self-publication, Athens.

Filippidou, E., Koutsouba, M., \& Tyrovola, V. (2008). Experience and Revival of Tradition. The Transformation of dance from co-presentation to representation in Pentalofos of Evros, Proceedings of the 22nd World Congress on Dance Research, A $\theta$ ńva: CID.

Filippou, F. (2015). The first woman's dancer improvisation in the area of Roumlouki (Alexandria) through the dance "Tis Marias". Ethnologhia on - line. An Annual Scholarly Electronic Journal, Published by the Greek Society for Ethnology, 6, 1-24.

Gilbert, A. G. (2015). Creative Dance for All Ages (2nd Ed.) Human Kinetics.

Gilbert, A. G., \& Rossano, A. (2006). Brain-compatible dance education. Reston, VA: National Dance Association.

Haselbach, B. (1979). Improvisation, Tanz, Bewegung. Verlag Klett Stuttgart. Germany.

Hoerburger, F. (1968). Once again: On the concept of "folk dance". Journal of the International Folk Music Council, 20, 30-14.

Hoerburger. F., (1965). Folk dance survey. International Folk Music Journal, 17, 7-8.

Kapsalis, A. (1977). Creativity - Psychological research and pedagogic action. Journal School and Life, Athens, 1, 4-18.

Kealiinohomokou, J. (1972). Folk dance. In Dorson R., Folklore and folklife. An introduction (p. 381-404). Chicago: Chicago University Press.

Kiriakidou-Nestoros, A. (1993). Folklore Studies, II, Poria, Athens. 
Koutsouba, M. (1991). The Greek Dance Groups of Plaka: A Case of "Airport Art”. Unpublished M.A. Dissertation, University of Surrey, Surrey, UK.

Koutsouba, M. (2000). Stylistic analysis in Greek traditional dance, (Ed.) Propompos. In: Culture and Art seven essays on dance, 30-77. Athens. Greece.

Koutsouba, M. (2003). Determination of the competent scientific field. In Nikos Gyftoulas et al., Arts II: Review of Greek Music and Dance: Theory of Dance-Greek Dance Act: Ancient and Middle Years, 4, Patras: Hellenic Open University, 97-102.

Koutsouba, M. (2007). Structural analysis for Greek folk dance. A methodology. In Adrianne L. Kaeppler and Elsie I. Dunin (eds.) Dance Structures: Perspectives on the Analysis of Human Movement, Budapest: European Folklore Institute, 253-276.

Koutsouba, M. (2009). The dynamics of Greek traditional dance in transcultural education. Journal Educational Community, 52, 38-41.

Koutsouba, M. (2010b). Teaching Greek traditional dances within contemporary educational contexts. In I. Dimas V. Tyrovola, \& M. Koutsouba, Greek Dance: consideration of speech, writing and its teaching, (Editors are the writers), Athens, 101-113.

Laban, R. (1981). Der moderne Ausdruckstanz in der Erziehung. Wilhelmshaven.

Lai Keun, L., \& Hunt, P. (2006). Creative dance: Singapore children's creative thinking and problem-solving responses. Research in Dance Education, 7(01), 35-65.

Loutzaki, R. (1985). Traditional dance in Greece. Philoxenia. Thessaloniki.

Loutzaki, R. (1989). Dance as Cultural Message: A Study of Dance Style Among the Greek Refugees from Northern Thrace in Mikro Monastiri, Neo Monastiri and Aeginion, Ph.D. Thesis. Belfast: The Queen's University of Belfast.

Lydaki, A. (2001). Qualitative methods of social research.Kastaniotis Editions. Athens

Lydaki, A. (2008). Dancing phenomenon and social reality. Research methods. Available on website: http://www.dancearchive.gr/article.php?id=13.

Lykesas, G. (2002). Teaching Greek traditional dance in primary school with the method of Music and movement education]. Ph.D. thesis. Thessaloniki: Aristotle University of Thessaloniki, Greece.

Lykesas, G. (2016). Ethnographic research on the music and dance tradition of Ikarian island-a timeless evolution -a dancing approach of the "Ikariotikos dance". Mediterranean Journal of Social Sciences, 7(2), S1, 11-19.

Lykesas, G. Tsapakidou, A., \& Tsompanaki, E. (2014). Creative Dance as a Means of Growth and Development of Fundamental Motor Skills for Children in First Grades of Primary Schools in Greece. Asian Journal of Humanities and Social Studies, 02(01), 211-218.

Lykesas, G., \& Papadopoulou, S. (2007). A teaching approach proposal of Greek traditional dances in school practice through music/movement education. Music in $1^{\text {st }}$ grade, 62-69.

Lykesas, G., \& Zachopoulou, E. (2006). Music and movement education as a form of motivation in teaching Greek traditional dances. Perceptual and Motor Skills, 102, 552-562.

Lykesas, G., \& Koutsouba, M. (2008). The teaching of Greek traditional dance in school education with the adoption of creative methods of teaching. Journal of Health and Sport Performance, 3, 37-49.

Lykesas, G., \& Tyrovola, V. (2007b). The Position of Traditional Dance in Primary School Curricula and its Implementation in practice. Music and pedagogics Journal, 5, 102-116.

Lykesas, G., Koutsouba, M., \& Tyrovola, B. (2010). Comparison of the teacher and child-centred methods of teaching Greek traditional dance in elementary education in Greece. International Journal of Physical Education, XLVII(3), 25-33.

Lykesas, G., Koutsouba, M., \& Tyrovola, V. (2009). Creativity as an approach and teaching method of traditional Greek dance in secondary schools. Studies in Physical Culture \& Tourism, 16(2), 207-214.

Lykesas, G., Papavlou, A., \& Papamichail, P. (1999). The evolutionary course of the Greek traditional dance from its natural place, the village, in school Physical Education. Proceedings of the 1st Panhellenic Congress of Folk Culture, Serres, Greece, 95-99.

Lykesas, G., Semaltiannou, E., Konstantinidou, M., \& Papadopoulou, D. S. (2004). Views of physical education instructors on teaching Greek traditional dances in elementary education. Journal of Human Movement Studies, 46, 171-187. 
Lykesas, G., Siskos, V., \& Zachariadou, Z. (2010b). The Effect of a Greek Traditional Dance Teaching Programme in the Improvement of High School Students Attitude in the Classroom and their Increased Satisfaction with Physical Education Lessons. Hellenic Scientific Dance Society (EL.EP.E.X.). Electronic Journal, 5, 18-36.

Lykesas, G., Tsapakidou, A., Konstantinidou, M., \& Papadopoulou S. D. (2002b). New approaches to teaching traditional Greek dances in elementary education. Journal of Human Movement Studies, 43, 429-442.

Matey, P. (1992). Rhythmos Editions, Hellenic Association of Music \& Movement Education Carl Orff, Athens

Meraklis, M. (1973). Contemporary Greek Culture. Ora, Athens.

Meraklis, M. (1989). Folk Issues, Bouras, Athens

Moore, J. L. S. (1984). Rhythm and Movement: An objective analysis of their association with music aptitude. Unpublished Doctoral Dissertation, pp. 58-145. University of North Carolina. Greensboro.

Morgan, W. P., Roberts, J. A., Brand, F., \& Feinerman, A. D. (1970). Psychological effects of chronic physical activity. Medicine and Science in Sports and Exercise, 2, 213-217.

Nahachewsky, A. (1995). Participatory and presentational dance as ethnochoreological categories, CORD Dance Research Journal, 27(1), 1-15.

Nahachewsky, A. (2001). Once again: On the concept of second existence of folk dance. Yearbook for Traditional Music. $33,17-28$.

Nitsiakos, B. (2003). Building Space and Time. Odysseus, Athens

Orff,C. (1963). The Schulwerk. Its origin and Aims. Music Educators Journal, 49(5), p.69-74.

Panopoulou, K., \& Goulimaris, D. (2010). Theoretical and Methodological Proposals in the Movement and Dance Relationship. Physical Education - Sports - Health, 24, 31-42.

Pita, R. (1998). Psychology of the Language. Ellinika Grammata, Athens.

Sanderson, P. (1988). Physical education and dance. Roberts T, ed., Encouraging expression: The arts in primary school. Cassell. London.

Sbonias, S. (1999). Introduction to Greek Culture. The Concept of Culture - Aspects of Greek Culture, Volume A, Patras, Hellenic Open University.

Siemens, M. (1969). A comparison of Orff and traditional instructional method in Music. Journal of Research in Music Education, 17(3), 272-285.

Stinson, S. (1988). Creative dance for preschool children. Journal of Physical Education, Recreation \& Dance, 59(7), 52-56.

Tsaousis, D. G. (1993). The Greek University at the Threshold of the $21^{\text {st }}$ Century, Gutenberg Editions, Athens.

Tyrovola, V. (1999). The Concept of Improvisation in Greek Folk Creation. In K. Sahinidis (edited), Traditional Dance and Folk Creation. Papazisis, Athens.

Tyrovola, V. (2001). Greek Dance - A Different Approach. Gutenberg Editions, Athens

Tyrovola, V. (2003). Dance: Morphological Approach and Formalism. In Basiliadis. Accompanying Texts: Greek Music and Dance, Thematic Unit "Arts II: Review of Greek Music and Dance», Patras, Hellenic Open University

Tyrovola, V. (2010). Art and Aesthetics. Aesthetics and the Art of Dance. In I. Dimas V. Tyrovola, \& M. Koutsouba, Greek Traditional Dance: consideration of speech, writing and its teaching, (Editors are the writers), Athens, 179-243.

Tyrovola, V., \& Koutsouba, M. (2006). Morphological Method of Teaching Greek Traditional Dance: the Example of the Dances of Pontos. Journal of Music in primary school, 1, 19-32.

Views and concerns. Oral Presentation at the $18^{\text {th }}$ International Conference of Physical Education \& Sports Science, School of Physical Education \& Sports Science, Komotini.

\section{Copyrights}

Copyright for this article is retained by the author(s), with first publication rights granted to the journal.

This is an open-access article distributed under the terms and conditions of the Creative Commons Attribution license which permits unrestricted use, distribution, and reproduction in any medium, provided the original work is properly cited. 